\title{
Optimal planning of energy storage system in active distribution system based on fuzzy multi-objective bi-level optimization
}

\author{
Rui LI $^{1}$ (i), Wei WANG ${ }^{1}$, Zhe CHEN $^{2}$, Xuezhi WU ${ }^{1}$
}

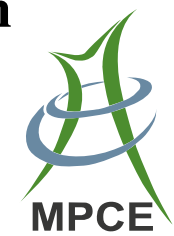

\begin{abstract}
A fuzzy multi-objective bi-level optimization problem is proposed to model the planning of energy storage system (ESS) in active distribution systems (ADS). The proposed model enables us to take into account how optimal operation strategy of ESS in the lower level can affect and be affected by the optimal allocation of ESS in the upper level. The power characteristic model of micro-grid (MG) and typical daily scenarios are established to take full consideration of time-variable nature of renewable energy generations (REGs) and load demand while easing the burden of computation. To solve the bi-level mixed integer problem, a multi-subgroup hierarchical chaos hybrid algorithm is introduced based on differential evolution (DE) and particle swarm optimization (PSO). The modified IEEE-33 bus benchmark distribution system is utilized to investigate the availability and effectiveness of the proposed model and the hybrid algorithm. Results indicate that the planning
\end{abstract}

CrossCheck date: 10 July 2017

Received: 30 June 2016/ Accepted: 10 July 2017/Published online: 4 December 2017

(C) The Author(s) 2017. This article is an open access publication

$\triangle$ Rui LI

lirui_ee@bjtu.edu.cn

Wei WANG

wwang2@bjtu.edu.cn

Zhe CHEN

zch@et.aau.dk

Xuezhi WU

xzhwu@bjtu.edu.cn

1 National Active Distribution Network Technology Research Center, Beijing Jiaotong University, Beijing 100044, China

2 Department of Energy Technology, Aalborg University, DK9220 Aalborg, Denmark model gives an adequate consideration to the optimal operation and different roles of ESS, and has the advantages of objectiveness and reasonableness.

Keywords Active distribution system, Energy storage system, Optimal planning, Bi-level programming, Fuzzy multiple objective

\section{Introduction}

For the purpose of energy security and environmental benefits, a rapid growth has been experienced in the integration of REGs into distribution networks, mainly wind generation (WG) and photovoltaic (PV). However, due to natures of intermittent and difficult prediction, REGs pose new challenges to the reliability of distribution networks. In this regard, MGs and ADSs are introduced and perceived to be key technologies to alleviate aforementioned challenges [1-4].

As a comprehensive energy unit, MG can integrate multiple REGs and be managed autonomously. In addition, multiple MGs in ADSs can share distributed energy resources and operate them in close coordination. Therefore, multiple MGs in ADSs can improve operation features and have significant merits for ADSs [5, 6]. In this architecture, distributed ESSs (DESSs) in MGs and mass ESSs (MESSs) in ADSs perform multiple important roles, such as network upgrade deferral, frequency-voltage control, power quality and reliability improvement, and alleviating the fluctuation of REGs [7, 8]. However, the large costs of ESS lead to the cost ineffectiveness of ADSs. Therefore, ESS should be properly sized and sited according to optimal costs while satisfying the load demand. 
Optimal planning of ESS has been previously studied in the literature of different fields, such as MGs [9-11], distribution networks [12-18], and large-scale power plants [19-22]. In terms of MGs, an optimal sizing method in [9] is proposed for the wind solar battery hybrid power system, considering two working modes of stand-alone and gridconnected. A sub-period optimization strategy is utilized to calculate the battery capacity. Authors in [11] use PSO to optimize the power rating and energy capacity of ESS for frequency control of a stand-alone MG.

For distribution networks, to accommodate spilled wind energy, a multi-step method based on the optimal power flow is presented in [13] for allocation of ESS to minimize the annual electricity cost. Authors in [14] explore a multiobjective allocation model of ESS in ADSs for sake of peak shaving, voltage quality improvement, and power self-regulation capacity. A weighted minimum module ideal point method is proposed to simplify the multi-objective problem. A chance constrained optimal model is proposed in [16] to determine the sizing and sitting of ESS. The model adopts minimizing investment and operation costs as the objective while meeting the constraint of wind utilization level. Research [17] proposes an optimal model to determine the location, capacity, and power rating of ESS in ADSs. The model takes roles of ESS into account based on the short-term optimal power flow. The roles are modeled as different costs and the penalty factor in the objective function. In [18], authors extend their work in [17] to take electric vehicles (EVs) into account. A point estimate method serves to tackle the uncertainties of load, REGs, and EVs.

In terms of large scale power plants, a two-steps cooptimization model is proposed to determinate the suitable sizing and control of ESS for the hybrid system of PV \& ESS in [20]. Authors in [21] propose operation models of ESS to maximize REGs revenues, and sizing models of ESS to minimize costs of the hybrid system.

Regarding the above literature review, it is clear that many optimal allocation models of ESS have been proposed. However, it is worth noticing a common drawback that most of the planning models do not take full consideration for the operation of ESS. For example, some straightforward models are used to represent the operation process with one objective, or they adopt the weighting method to deal with multiple objectives. Thus, multiple crucial roles of ESS in ADSs can't be represented adequately.

In addition, another drawback in the aforementioned literature is related to the models of REGs: probabilistic models are often adopted to reflect the intermittent nature of WG and PV, such as [12, 16, 22], which can't give full expression to the time-variable nature of multiple REGs.
Furthermore, these models are not suitable for the simulation of ESS.

These two main drawbacks lead to the distortion of ESS operating state in planning models, contrary to the principle of ADS planning [23], where operation models of active managements, such as the operation of ESS, should be integrated into planning models of ADS to get more optimal and reasonable planning solutions.

This paper focuses on the planning problem of MESS in ADSs, which contains WG, PV, and multi-MGs. In order to properly determine the sizing, siting and type of ESS, a fuzzy multi-objective bi-level optimal planning model is proposed with several primary highlights.

Firstly, to capture operation aspects which can affect planning stage, a bi-level model is adopted to achieve the collaborative optimization between planning and operation of ESS. For the purpose of giving expression to multiple roles of MESS in ADSs, a fuzzy multi-objective model is adopted, which consists of peak load shaving, restraining volatility, and improving the reserve capability of ESS.

Moreover, time-dependent data are adopted to represent time variable nature of REGs, MGs and ESSs instead of probabilistic models. To ease the computational burden, these time-series profiles are recognized and clustered into typical daily scenarios based on the fuzzy $\mathrm{C}$ mean (FCM) clustering algorithm and multiple scenarios technique.

Finally, to solve this bi-level mixed integer optimization problem efficiently, a multi-subgroup hierarchical chaos algorithm is introduced based on DE and PSO.

The paper is organized as follows. Section 2 provides the framework of the planning model. Section 3 presents methods to establish the power characteristic model of MG and typical daily scenarios. In Section 4, we formulate the fuzzy multi-objective bi-level model. A multi-subgroup hierarchical chaos hybrid approach is further developed in Section 5. Then, the computational results and discussions are given in Section 6. Section 7 concludes this paper with several remarks.

\section{Framework of optimal planning model of ESS}

The planning of ESS in ADSs should consider not only minimizing of costs, but also significant roles of ESS. To demonstrate multiple roles of ESS, two statuses of ADSs should be considered: 1) the normal status with roles of peak load shaving and restraining volatility, 2) the failure status with the responsibility for system support. Moreover, the time-variable nature of load and REGs is another essential factor that needs to be considered.

Based on the discussion above, the framework of the optimal planning model of ESS is described in Fig. 1, where $F_{\text {upper }}$ and $f_{\text {lower }}$ are objectives of the upper level and 


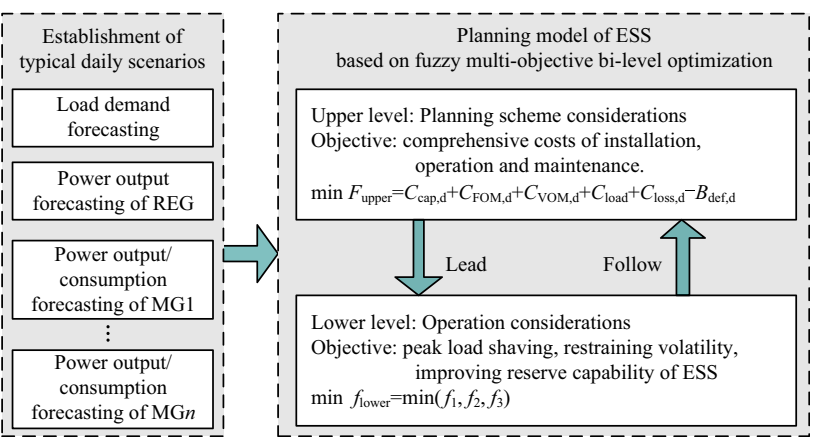

Fig. 1 Framework of bi-level optimal planning model of ESS

the lower level, respectively; $C_{\mathrm{cap}, \mathrm{d}}, C_{\mathrm{FOM}, \mathrm{d}}, C_{\mathrm{VOM}, \mathrm{d}}$ are the diurnal capital cost, the diurnal fixed operating and maintenance $(\mathrm{O} \& M)$ cost and the diurnal variable $O \& M$ cost of ESS, respectively; $C_{\text {load,d }}$ and $C_{\text {loss,d }}$ are diurnal costs of load demand and network losses, respectively; $B_{\text {def,d }}$ denotes the benefits got by deferral upgrade; $f_{1}, f_{2}$, and $f_{3}$ represent the three objectives of the lower level.

The left side of Fig.1 describes the procedure to establish these scenarios: after annual forecasting data of REGs and load are processed by FCM, the typical daily scenarios are developed by multiple scenarios technique. These typical daily scenarios preserve the chronological sequence of power outputs of REGs and power consumptions of load, which allows representing eventual chronological aspects related to ESS scheduling [23].

The right side provides the fuzzy multi-objective bilevel planning model. Each level of bi-level model has its objectives and decision spaces affected by variables controlled at another level. Meanwhile, the execution of decisions is sequential, from higher level to lower level [24]. These features enable bi-level model to be suitable for the planning of ADS. For the planning aspect, minimizing the total costs of the ADS and ESS serves as the objective of the upper level. For the operation aspect, a fuzzy multiobjective model is introduced to obtain ESS scheduling in the lower level, which will be fed back to the upper level to calculate operation costs by power flow calculation at hourly time-steps for every daily scenario.

The most prominent roles of ESS to ADSs are elected to be optimal objectives: 1) peak load shaving and valley load filling aiming at deferral of system investment, 2) restraining the volatility with the purpose of alleviating the fluctuation of load and REGs, and 3) improving the reserve capability of ESS seeking to take some degree of responsibility for system support.

\section{Establishment of typical daily scenarios}

\subsection{Power characteristic model of MG}

The power characteristic of MG is bundled with the allocation of MG, as well as the operation strategy [5]. In this work, the wind solar battery hybrid MGs are adopted, and maximizing the utilization of REGs is adopted to be the strategy of DESS in MGs. Meanwhile, the electricity price is also an important factor to be considered.

1) When the output of REGs is more than the local load demand, the DESS should be charged. At this moment, if this surplus power is larger than the charging demand of DESS, DESS is charged by REGs alone. If this surplus power is smaller than the charging demand of DESS, and the electricity price of the external system is lower than the contract price of REGs, DESS is charged by both REGs and the external system. If this surplus power is smaller than the charging demand of DESS, and the electricity price of the external system is higher than the contract price of REGs, DESS is charged by REGs alone, or charged by both REGs and the external system until the SOC of DESS reaches a pre-set value $(\lambda)$ in case of need.

2) When the output of REGs cannot meet the local load demand of MG, and the DESS together with REGs has no enough energy to meet the local load demand, the DESS starts to be charged with the external system until the SOC of DESS reaches a pre-set value $(\lambda)$.

3) When the output of REGs cannot meet the local load demand of MG, and the DESS together with REGs has enough energy to meet the local load demand, the DESS starts to discharge and has the priority to meet load demand before the external system.

The power model of DESS is formulated as follows:

$$
\begin{gathered}
P_{\mathrm{DES}}(t)=P_{\mathrm{C}}^{\max } \quad 0 \leq P_{\mathrm{C}}^{\max } \leq \Delta P(t) \\
P_{\mathrm{DES}}(t)=P_{\mathrm{C}}^{\max } \quad\left(0 \leq \Delta P(t)<P_{\mathrm{C}}^{\max }\right) \&\left(E P_{\mathrm{G}}(t) \leq E P_{\mathrm{R}}\right) \\
P_{\mathrm{DES}}(t)=\min \left\{P_{\mathrm{DES}}^{\mathrm{R}}, \frac{\left(E_{\mathrm{DES}, \lambda}-E_{\mathrm{DES}}(t-1)\right) \eta_{\mathrm{C}}}{\Delta t}\right\} \\
\left(0 \leq \Delta P(t)<P_{\mathrm{C}}^{\max }\right) \&\left(E P_{\mathrm{G}}(t)>E P_{\mathrm{R}}\right) \&\left(S O C_{\mathrm{DES}}(t-1)<\lambda\right) \\
P_{\mathrm{DES}}(t)=\Delta P(t) \\
\quad\left(0 \leq \Delta P(t)<P_{\mathrm{C}}^{\max }\right) \&\left(E P_{\mathrm{G}}(t)>E P_{\mathrm{R}}\right) \&\left(S O C_{\mathrm{DES}}(t-1) \geq \lambda\right)
\end{gathered}
$$




$$
\begin{aligned}
& P_{\mathrm{DES}}(t)=\min \left\{P_{\mathrm{DES}}^{\mathrm{R}}, \frac{\left(E_{\mathrm{DES}, \lambda}-E_{\mathrm{DES}}(t-1)\right) \eta_{\mathrm{C}}}{\Delta t}\right\} \\
& (\Delta P(t)<0) \&\left(P_{\mathrm{REG}}^{\mathrm{MG}}(t)+P_{\mathrm{D}}^{\mathrm{max}}(t)<P_{\mathrm{load}}^{\mathrm{MG}}(t)\right) \\
& \&\left(S O C_{\mathrm{DES}}(t-1)<\lambda\right)
\end{aligned}
$$

In other cases, the DESS discharges.

$$
P_{\mathrm{DES}}(t)=\min \left\{|\Delta P(t)|, P_{\mathrm{D}}^{\max }\right\}
$$

where

$$
\begin{aligned}
& P_{\mathrm{C}}^{\max }=\min \left\{P_{\mathrm{DES}}^{\mathrm{R}}, \frac{\left(E_{\mathrm{DES}}^{\max }-E_{\mathrm{DES}}(t-1)\right)}{\Delta t \times \eta_{\mathrm{C}}}\right\} \\
& P_{\mathrm{D}}^{\max }=\min \left\{P_{\mathrm{DES}}^{\mathrm{R}}, \frac{\left(E_{\mathrm{DES}}(t-1)-E_{\mathrm{DES}}^{\min }\right) \eta_{\mathrm{D}}}{\Delta t}\right\} \\
& E_{\mathrm{DES}}^{\max }=E_{\mathrm{DES}}^{\mathrm{R}} S O C_{\mathrm{DES}}^{\max } \\
& E_{\mathrm{DES}}^{\min }=E_{\mathrm{DES}}^{\mathrm{R}} S O C_{\mathrm{DES}}^{\min } \\
& E_{\mathrm{DES}}(t)= \begin{cases}E_{\mathrm{DES}}(t-1)+P_{\mathrm{DES}}(t) \Delta t \eta_{\mathrm{C}} & P_{\mathrm{DES}}(t)>0 \\
E_{\mathrm{DES}}(t-1)+\frac{P_{\mathrm{DES}}(t) \Delta t}{\eta_{\mathrm{D}}} & P_{\mathrm{DES}}(t) \leq 0\end{cases}
\end{aligned}
$$

$t=1,2, \ldots, 24 ; \Delta t$ is the duration of the commitment interval, in hours (1 hour); $P_{\mathrm{DES}}(t), E_{\mathrm{DES}}(t)$ and $S O C_{\mathrm{DES}}(t)$ are charging/discharging power, energy stored in the battery bank, and state of charge (SOC) of DESS at time$t$, respectively; $\eta_{\mathrm{C}}$ and $\eta_{\mathrm{D}}$ are efficiencies of charging and discharging, respectively; $\Delta P(t)$ is the difference between REGs output and load demand in MG; $P_{\mathrm{DES}}^{\mathrm{R}}$ and $E_{\mathrm{DES}}^{\mathrm{R}}$ are the power rating and the energy capacity of DESS, respectively; $S O C_{\mathrm{DES}}^{\max }$ and $S O C_{\mathrm{DES}}^{\min }$ denote the permissible range of SOC; $E_{\mathrm{DES}}^{\max }$ and $E_{\mathrm{DES}}^{\min }$ denote the permissible range of energy stored of DESS; $P_{\mathrm{C}}^{\max }$ and $P_{\mathrm{D}}^{\max }$ are the maximums of charging/discharging power under constraints of SOC, respectively; $E_{\mathrm{DES}, \lambda}$ is the energy stored of DESS when $\mathrm{SOC}=\lambda ; E P_{\mathrm{G}}(t)$ and $E P_{\mathrm{R}}$ are the electricity prices of the external system and contract price of REGs, respectively.

Due to simple constructions of MGs, the power losses in MGs are ignored. Thus, the power characteristic model of MG can be expressed as an electrical unit by (12).

$P_{\mathrm{MG}}(t)=P_{\text {load }}^{\mathrm{MG}}(t)+P_{\mathrm{DES}}(t)-P_{\mathrm{REG}}^{\mathrm{MG}}(t)$

where $P_{\mathrm{REG}}^{\mathrm{MG}}(t)$ and $P_{\mathrm{load}}^{\mathrm{MG}}(t)$ are the REGs output and the local load demand in MG at time- $t$, respectively.

\subsection{Establishment of typical daily scenarios}

Firstly, these annual time-dependent data are segmented into 365 daily intervals. Then, these 365 daily patterns of REGs power output, and load demand are clustered into typical daily profiles with corresponding probabilities by FCM, respectively. It means that the daily variation trends of these 365 daily patterns serve as the features of clusters.

Then, these typical daily scenarios are established by the multiple scenarios technique based on these clustered data. Finally, these representative typical daily scenarios are divided into elementary intervals (1 hour) and the power flow calculation are repeated sequentially for each of them to calculate operation costs.

The cluster number can be determined by the clustering validity index $I_{M}$ [25]. A larger value of $I_{M}$ implies wellseparated clusters and a better solution.

By this means, typical daily scenarios can be extracted from these annual prediction data and assumed sufficiently representative of the behaviors of REGs and load demand. Thus, the operation process can be simulated more precisely and take the time-variable nature of REGs and load demand into consideration, while easing the burden of planning computation.

\section{Problem formulation}

\subsection{Upper level model: planning considerations}

The control vector of the upper level consists of the power rating $\left(P_{\mathrm{ESS}}^{\mathrm{R}}\right)$, the energy capacity $\left(E_{\mathrm{ESS}}^{\mathrm{R}}\right)$ and the location $\left(L_{\mathrm{ESS}}\right)$ of ESS. The model is described as follows.

\subsubsection{Objective function of upper level}

$$
\begin{aligned}
& \min F_{\text {upper }}=\min C_{\text {total }}\left(P_{\mathrm{ESS}}^{\mathrm{R}}, E_{\mathrm{ESS}}^{\mathrm{R}}, L_{\mathrm{ESS}}\right) \\
& \quad=\left(C_{\mathrm{cap}, \mathrm{d}}+C_{\mathrm{FOM}, \mathrm{d}}+C_{\mathrm{VOM}, \mathrm{d}}+C_{\text {load }, \mathrm{d}}+C_{\text {loss }, \mathrm{d}}-B_{\mathrm{def}, \mathrm{d}}\right)
\end{aligned}
$$

Implications and calculation methods of these items are illustrated below.

1) Diurnal capital cost of ESS

The capital cost of ESS can be represented as a function of two main parts. One is related to the power conversion system cost, and another is related to all the costs to build energy storage banks or reservoirs, shown as (14).

$C_{\text {cap }, \mathrm{d}}=\frac{1}{365}\left(C_{\mathrm{PCS}} \times P_{\mathrm{ESS}}^{\mathrm{R}}+C_{\mathrm{B} \& \mathrm{R}} \times E_{\mathrm{ESS}}^{\mathrm{R}}\right) C R F$

where $C_{\mathrm{PCS}}$ and $C_{\mathrm{B} \& \mathrm{R}}$ are the annualized per unit cost of power conversion system and the annualized per unit cost of energy storage section, respectively. Capital recovery factor $(C R F)$ is the ratio used to calculate the present value of equal annual cash flows, shown as (15), and subjected to the interest rate $r$ during the life time $T_{\mathrm{ESS}}$. 
$C R F=\frac{r(1+r)^{T_{\mathrm{ESS}}}}{(1+r)^{T_{\mathrm{ESS}}}-1}$

2) Diurnal operating and maintenance costs of ESS

Diurnal O\&M costs include two main parts: the fixed O\&M cost $\left(C_{\text {FOM.d }}\right)$ and the variable O\&M cost $\left(C_{\text {VOM.d }}\right)$ [26], expressed as(16) and (17), respectively.

$C_{\mathrm{FOM}, \mathrm{d}}=\frac{1}{365} C_{\mathrm{FOM}, \mathrm{a}} P_{\mathrm{ESS}}^{\mathrm{R}}$

$C_{\mathrm{VOM}, \mathrm{d}}=n C_{\mathrm{VOM}} P_{\mathrm{ESS}}^{\mathrm{R}}$

where $C_{\text {FOM.a }}$ is the annualized per unit cost of fixed O\&M; $C_{\text {VOM }}$ is the hourly per unit cost of variable O\&M; $n$ is the diurnal operating hour of ESS.

3) Diurnal operating costs of regional ADS

The diurnal operating costs of regional $\operatorname{ADS}\left(C_{\mathrm{ope}, \mathrm{d}}\right)$, including the costs of load demand $\left(C_{\text {load,d }}\right)$ and network losses $\left(C_{\text {loss,d }}\right)$, can indicate the economic efficiency of planning schemes. Moreover, time-of-use (TOU) electricity prices are taken into account.

$$
\begin{aligned}
& C_{\text {load }, \mathrm{d}}=\sum_{t \in t_{\mathrm{p}}} C_{\mathrm{p}} P_{\mathrm{NL}}(t)+\sum_{t \in t_{\mathrm{f}}} C_{\mathrm{f}} P_{\mathrm{NL}}(t)+\sum_{t \in t_{\mathrm{v}}} C_{\mathrm{v}} P_{\mathrm{NL}}(t) \\
& C_{\text {loss }, \mathrm{d}}=\sum_{t \in t_{\mathrm{p}}} C_{\mathrm{p}} P_{\text {loss }}(t)+\sum_{t \in t_{\mathrm{f}}} C_{\mathrm{f}} P_{\text {loss }}(t)+\sum_{t \in t_{\mathrm{v}}} C_{\mathrm{v}} P_{\text {loss }}(t)
\end{aligned}
$$

where $C_{\mathrm{P}}, C_{\mathrm{f}}$ and $C_{\mathrm{v}}$ are TOU prices during peak hours $\left(t_{\mathrm{P}}\right)$, flat hours $\left(t_{\mathrm{f}}\right)$ and valley hours $\left(t_{\mathrm{v}}\right)$, respectively; $P_{\mathrm{NL}}(t)$ is the net load demand at time- $t$, which can be expressed as (20); $P_{\text {loss }}(t)$ is the active power loss at time- $t$, which can be calculated by the power flow calculation.

$P_{\mathrm{NL}}(t)=P_{\text {load }}(t)+P_{\mathrm{MG}}(t)+P_{\mathrm{ESS}}(t)-P_{\mathrm{REG}}(t)$

where $P_{\text {load }}(t)$ is the load demand of ADS at time- $t$; $P_{\mathrm{REG}}(t)$ is the power output of REGs at time- $t ; P_{\mathrm{MG}}(t)$ and $P_{\mathrm{ESS}}(t)$ are the power output/consumption of MG and ESS at time- $t$, respectively.

4) Diurnal benefits of upgrade deferral

The integration of ESS enables us to release the capacity of ADSs and defer the upgrade of system, the benefits of which $\left(B_{\text {def,d }}\right)$ can be presented in (21).

$B_{\mathrm{def}, \mathrm{d}}=\frac{1}{365} C_{\mathrm{DE}, \mathrm{a}}\left(P_{\mathrm{NL}}^{\max }-P_{\mathrm{NL}}^{\max }\right) C R F$

where $C_{\mathrm{DE}, \mathrm{a}}$ is the annualized per unit capital cost of distribution equipment; $P_{\mathrm{NL}}^{\max }$ and $P_{\mathrm{NL}^{\prime}}^{\max }$ are maximum of net load without ESS and with ESS, respectively.

It should be noticed that $C_{\mathrm{VOM} . \mathrm{d}}, C_{\text {load,d }}, C_{\text {loss,d }}$, and $B_{\text {def,d }}$ depend on the operation of ESS and the regional
ADS in different daily scenarios. Therefore, the objective function of the upper level should be adapted by (22).

$$
\begin{aligned}
& \min F_{\text {upper }}=\min C_{\text {total }}\left(P_{\mathrm{ESS}}^{\mathrm{R}}, E_{\mathrm{ESS}}^{\mathrm{R}}, L_{\mathrm{ESS}}\right) \\
& \quad=C_{\mathrm{cap}, \mathrm{d}}+C_{\mathrm{FOM}, \mathrm{d}}+\sum_{s=1}^{S} \eta_{s}\left(C_{\mathrm{VOM}, s}+C_{\mathrm{load}, s}+C_{\mathrm{loss}, s}-B_{\mathrm{def}, s}\right)
\end{aligned}
$$

where $\eta_{s}$ is the probability of scenario $s ; C_{\mathrm{VOM} . s}$ is the diurnal variable O\&M cost of ESS in scenario $s ; C_{\text {load, }, s}$, $C_{\text {loss }, s}$ and $B_{\text {def, } s}$ are costs of the diurnal load demand, network losses and benefits in scenario $s$, respectively.

\subsubsection{Constraints of upper level}

Main constraints of the upper level are given from (23) to (27).

1) Active/reactive power balance equation

$S_{\text {load }}(t)+S_{\text {loss }}(t)+S_{\mathrm{MG}}(t)+S_{\mathrm{ESS}}(t)=S_{\mathrm{Grid}}(t)+S_{\mathrm{REG}}(t)$

where $S_{\text {load }}(t), S_{\mathrm{ESS}}(t), S_{\mathrm{REG}}(t), S_{\mathrm{MG}}(t)$ and $S_{\mathrm{Grid}}(t)$ are the electric load, charge/discharge load of ESS, REG output, MG output/consumption and power exchange of main grid at time- $t$, respectively; $S_{\text {loss }}(t)$ is the network power losses.

2) Power flow equations

$$
\begin{aligned}
& P_{i}(t)=U_{i}(t) \sum_{j=1}^{N_{\text {bus }}} U_{j}(t)\left(G_{i j} \cos \theta_{i j}(t)+B_{i j} \sin \theta_{i j}(t)\right) \\
& Q_{i}(t)=U_{i}(t) \sum_{j=1}^{N_{\text {bus }}} U_{j}(t)\left(G_{i j} \sin \theta_{i j}(t)-B_{i j} \cos \theta_{i j}(t)\right)
\end{aligned}
$$

where $P_{i}(t)$ and $Q_{i}(t)$ are the active and the reactive power of bus $i$, respectively; $U_{i}(t)$ is the voltage magnitude of bus $i ; G_{i j}$ and $B_{i j}$ are the transfer conductance and the susceptance between bus $i$ and bus $j$, respectively; $\theta_{i j}(t)$ is the voltage angle difference between bus $i$ and bus $j$.

3) Security constraints

Security constraints include the constraints of the bus voltage magnitudes and transmission line loadings.

$U_{i, \min } \leq U_{i}(t) \leq U_{i, \max }$

$S_{l}(t) \leq S_{l, \max }$

where $U_{i, \min }$ and $U_{i, \max }$ denote the permissible range of voltage magnitude for bus $i ; S_{l, \max }$ is the maximum of power flow for line $l$. 


\subsection{Lower level model: operation considerations}

The control vector of the lower level is constituted by charging/discharging power of ESS at time- $t$ in every typical scenario. The model is described as follows.

\subsubsection{Objective function of lower level}

The fuzzy multi-objective model serves as the objective function of the lower level, considering peak load shaving, restraining volatility, and improving the reserve capability of ESS, as given by (28) to (31).

1) Peak load shaving

Minimizing the variance of net load is adopted to represent the objective of peak load shaving, as given by (28).

$\min f_{1}=\min \frac{1}{24} \sum_{t=1}^{24}\left(P_{\mathrm{NL}}(t)-P_{\mathrm{NL} . \text { average }}\right)^{2}$

where $P_{\text {NL.average }}$ is the average of net load demand of ADS during the typical scenario.

2) Restraining volatility

Based on the ability to inject and absorb power quickly, ESS can be used to alleviate the negative impacts brought by fluctuations of REGs and load, given by (29).

$\min f_{2}=\min \sum_{t=2}^{24}\left(P_{\mathrm{NL}}(t)-P_{\mathrm{NL}}(t-1)\right)^{2}$

3) Improving reserve capability of ESS

When ADS malfunctions, ESS can provide some degree of power supply to the essential load, and participate in the service restoration. The reserve capability of ESS is introduced and defined as the maximum power which ESS can supply to ADS, subjected to operation constraints at time- $t$, expressed as (30).

$P_{\text {ava }}(t)=\min \left\{P_{\mathrm{ESS}}^{\mathrm{R}}, \frac{\left(E_{\mathrm{ESS}}(t-1)-E_{\mathrm{ESS}}^{\min }\right) \eta_{\mathrm{D}}}{\Delta t}\right\}$

where $E_{\mathrm{ESS}}(t)$ is the energy stored in the battery bank of ESS at time- $t ; E_{\mathrm{ESS}}^{\min }$ is the minimum of energy stored in the battery bank of ESS.

Maximizing the reserve capability of ESS serves as the third objective of the lower level, shown by (31).

$\min f_{3}=\min \left(1 / \sum_{t=1}^{24} P_{\mathrm{ava}}(t)\right)$

Aiming to get more reasonable optimization result, the fuzzy satisfaction-maximizing is selected to deal with the multi-objective problem [27].

\subsubsection{Constraints of lower level}

The constraints of the lower level are mainly operation constraints of ESS, including equality and inequality constraints, as given by (32) to (37).

1) Equality constraints of ESS periodical behavior

$$
E_{E S S}(t)= \begin{cases}E_{\mathrm{ESS}}(t-1)+P_{\mathrm{ESS}}(t) \Delta t \eta_{\mathrm{C}} & P_{\mathrm{ESS}}(t)>0 \\ E_{\mathrm{ESS}}(t-1)+\frac{P_{\mathrm{ESS}}(t) \Delta t}{\eta_{\mathrm{D}}} & P_{\mathrm{ESS}}(t) \leq 0\end{cases}
$$

2) Equality constraint of state transition

$$
\sum_{t=1}^{24}\left(P_{\mathrm{ESS}}(t) \Delta t \eta_{\mathrm{C}}+\frac{P_{\mathrm{ESS}}(t) \Delta t}{\eta_{\mathrm{D}}}\right)=0
$$

3) Inequality constraint of SOC

$$
S O C_{\mathrm{ESS}}^{\min } \leq S O C_{\mathrm{ESS}}(t) \leq S O C_{\mathrm{ESS}}^{\max }
$$

4) Inequality constraint of peak power

$$
-P_{\mathrm{ESS}}^{\mathrm{R}} \leq P_{\mathrm{ESS}}(t) \leq P_{\mathrm{ESS}}^{\mathrm{R}}
$$

5) Inequality constraints of power during $t_{\mathrm{P}}$ and $t_{\mathrm{v}}$

$$
\begin{array}{ll}
P_{\mathrm{ESS}}(t) \leq 0 & t \in t_{\mathrm{p}} \\
P_{\mathrm{ESS}}(t) \geq 0 & t \in t_{\mathrm{v}}
\end{array}
$$

where $S O C_{\mathrm{ESS}}(t)$ is SOC of ESS at time- $t ; S O C_{\mathrm{ESS}}^{\min }$ and $S O C_{\mathrm{ESS}}^{\max }$ denote the permissible range of SOC.

\section{Hybrid solution strategy for bi-level models}

From the mathematical perspective, the proposed model is a problem of bi-level nonlinear commitment optimization with mixed-integers. To address this problem, a multisubgroup hierarchical chaos hybrid algorithm (MHCDEPSO) is introduced based on DE and PSO on basis of [28].

\subsection{MHCDEPSO}

DE and PSO are effective intelligent algorithms to solve nonlinear multi-extrema optimization problems. However, PSO is easily trapped into the local optimal solution, and DE has the drawback of slow convergence speed. To tackle these problems, we combine them and introduce several improvement measures given as follows.

1) Multi-subgroup hierarchical structure

Every whole iteration consists of the base layer and the elite layer. Meanwhile, the population of every iteration in the base layer is divided into multi-subgroups, and each subgroup carries out DE operator respectively. To improve the information interaction among these subgroups, elite 
individuals of every subgroup are brought into the elite layer to form the elite population for PSO operator.

2) Tent chaos mapping

The tent mapping has better features of ergodicity and randomness, so the tent chaos mapping is applied to generate the initial population instead of random initialization method. Meanwhile, the chaos mutation operator is introduced to escape from the premature taking variance of fitness $\left(\sigma^{2}\right)$ as the criterion [29].

3) Adaptive coefficients of DE and PSO

To optimize the local search ability and the global search ability based on the number of iterations, an adaptive weight coefficient $(\omega)$ in PSO and an adaptive crossover probability $(C R)$ in DE are used instead of the constants, as given by (38) and (39).

$$
\begin{aligned}
& \omega(k)=\omega_{\max }-\left(\omega_{\max }-\omega_{\min }\right)\left(\frac{k}{k_{\max }}\right)^{2} \\
& C R(k)=C R_{\min }+\left(C R_{\max }-C R_{\min }\right) e^{-30\left(1-\frac{k}{k_{\max }}\right)^{h}}
\end{aligned}
$$

where $k$ is the number of iterations, and $k_{\max }$ is upper bound of $k ; \omega_{\max }$ and $\omega_{\min }$ denote the permissible range of $\omega ; C R_{\max }$ and $C R_{\min }$ denote the permissible range of $C R$; $h$ is an integer coefficient greater than 1 .

Hence, with the increase of $k, \omega(k)$ in PSO decreases and $C R(k)$ in DE increases, which will improve global searching ability in the beginning stages and local search ability in the end, respectively [30].

\subsection{Hybrid strategy based on MHCDEPSO and CPSO}

MHCDEPSO serves as the basic frame of the hybrid strategy to determine the allocation of ESS in the upper level. Chaos PSO serves as the algorithm embedded in the basic frame to obtain ESS scheduling in the lower level.

The flow charts are shown in Fig. 2 and Fig. 3. The * means the steps where chaos PSO embeds.

\section{Computational results and discussion}

\subsection{Parameters of test system}

To verify the effectiveness of the planning model and the hybrid solving strategy, simulation studies are carried out based on the modified IEEE-33 bus distribution network, as shown in Fig. 4. The total load demands of the ADS are 3.715 MW for active power and 2.300 Mvar for reactive power, and the reference voltage is $12.6 \mathrm{kV}$.

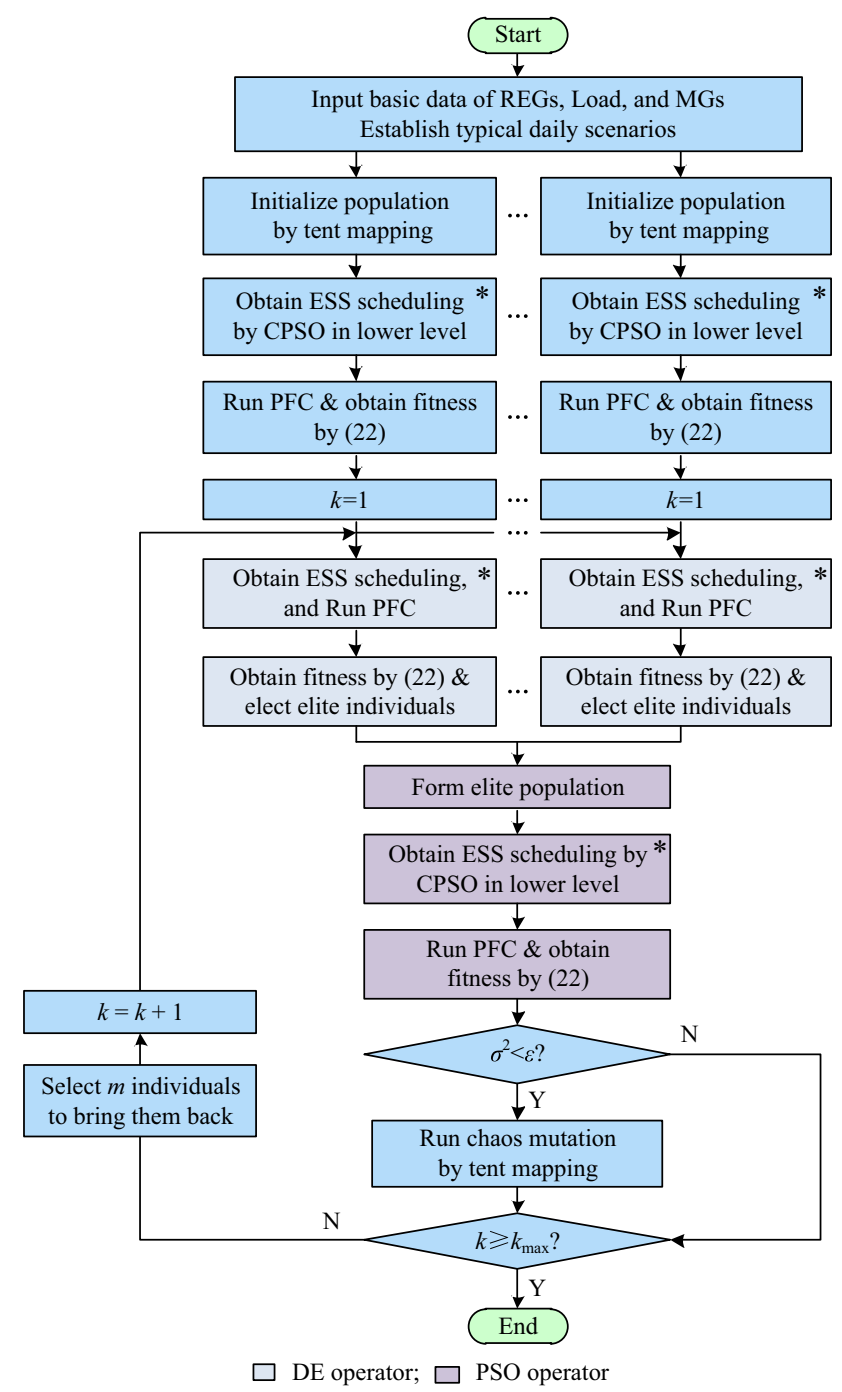

Fig. 2 Flow chart of the upper level based on MHCDEPSO

In order to utilize the power of REGs locally, PV and WG are allocated in Bus 7 and Bus 24, and three types of MGs, such as the residential area, the business service area, and the industrial area, are allocated in Bus 18, Bus 13 and Bus 22, respectively. Table 1 provides data of MGs [5]. Other parameters refer to the Appendix A.

Figure 5 shows the annual profiles of solar irradiance, and wind speed obtained by HOMER, and the load curve extracted from IEEE-RTS79 in [31].

Three types of ESS are selected to be candidates, including lead-acid battery (LAB), sodium-sulfur battery $(\mathrm{NaS})$ and li-ion (LIB). Parameters of them are provided in Table 2 [26]. The permissible ranges of power rating and energy capacity of ESS are $500-1000 \mathrm{~kW}$, and 500-3000 kWh, respectively. Buses 1-32 are candidate sites. 

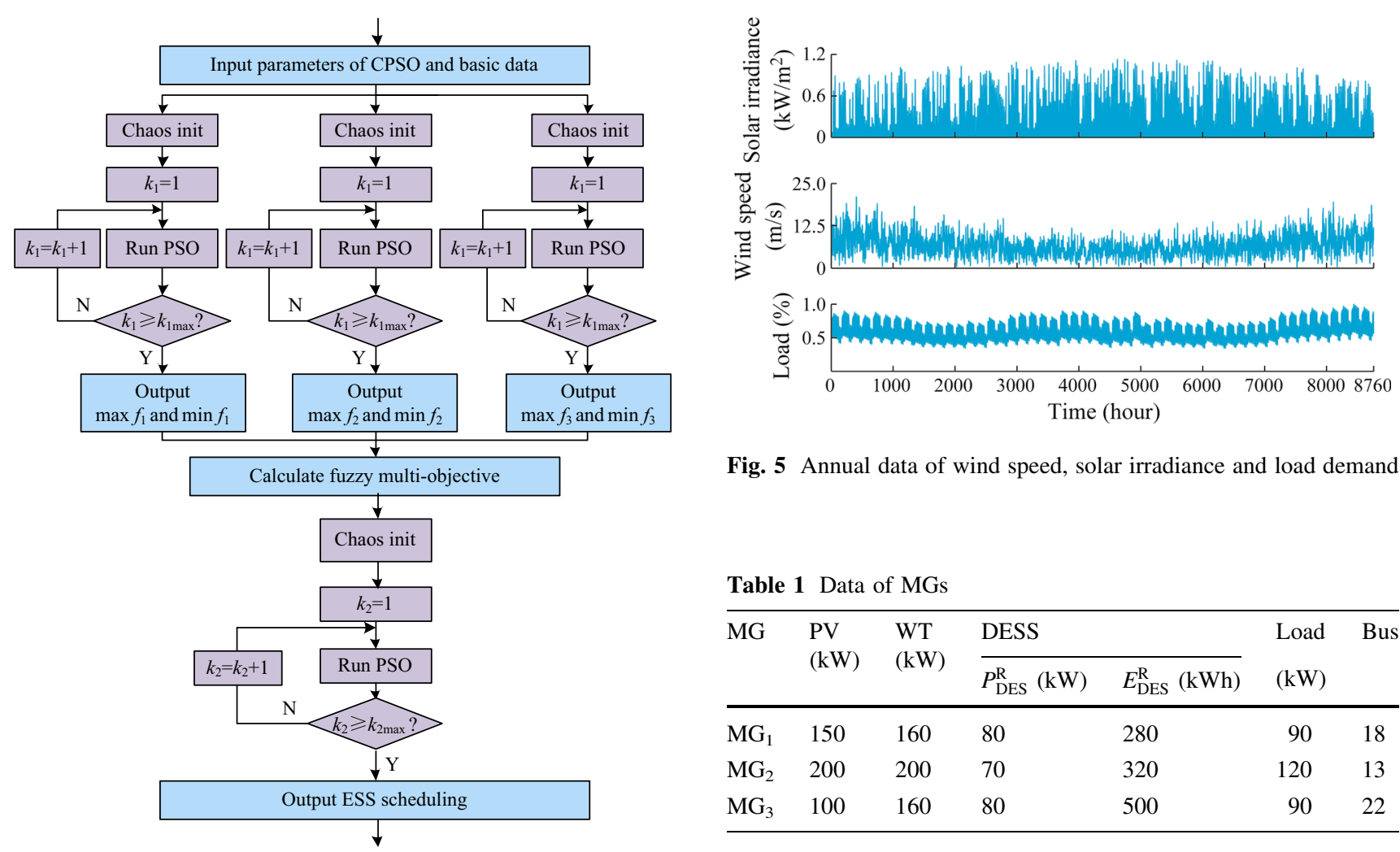

Fig. 5 Annual data of wind speed, solar irradiance and load demand

Table 1 Data of MGs

\begin{tabular}{|c|c|c|c|c|c|c|}
\hline \multirow[t]{2}{*}{ MG } & \multirow{2}{*}{$\begin{array}{l}\text { PV } \\
(\mathrm{kW})\end{array}$} & \multirow{2}{*}{$\begin{array}{l}\text { WT } \\
(\mathrm{kW})\end{array}$} & \multicolumn{2}{|l|}{ DESS } & \multirow{2}{*}{$\begin{array}{l}\text { Load } \\
(\mathrm{kW})\end{array}$} & \multirow[t]{2}{*}{ Bus } \\
\hline & & & $P_{\mathrm{DES}}^{\mathrm{R}}(\mathrm{kW})$ & $E_{\mathrm{DES}}^{\mathrm{R}}(\mathrm{kWh})$ & & \\
\hline $\mathrm{MG}_{1}$ & 150 & 160 & 80 & 280 & 90 & 18 \\
\hline $\mathrm{MG}_{2}$ & 200 & 200 & 70 & 320 & 120 & 13 \\
\hline $\mathrm{MG}_{3}$ & 100 & 160 & 80 & 500 & 90 & 22 \\
\hline
\end{tabular}

Fig. 3 Flow chart of the lower level based on CPSO

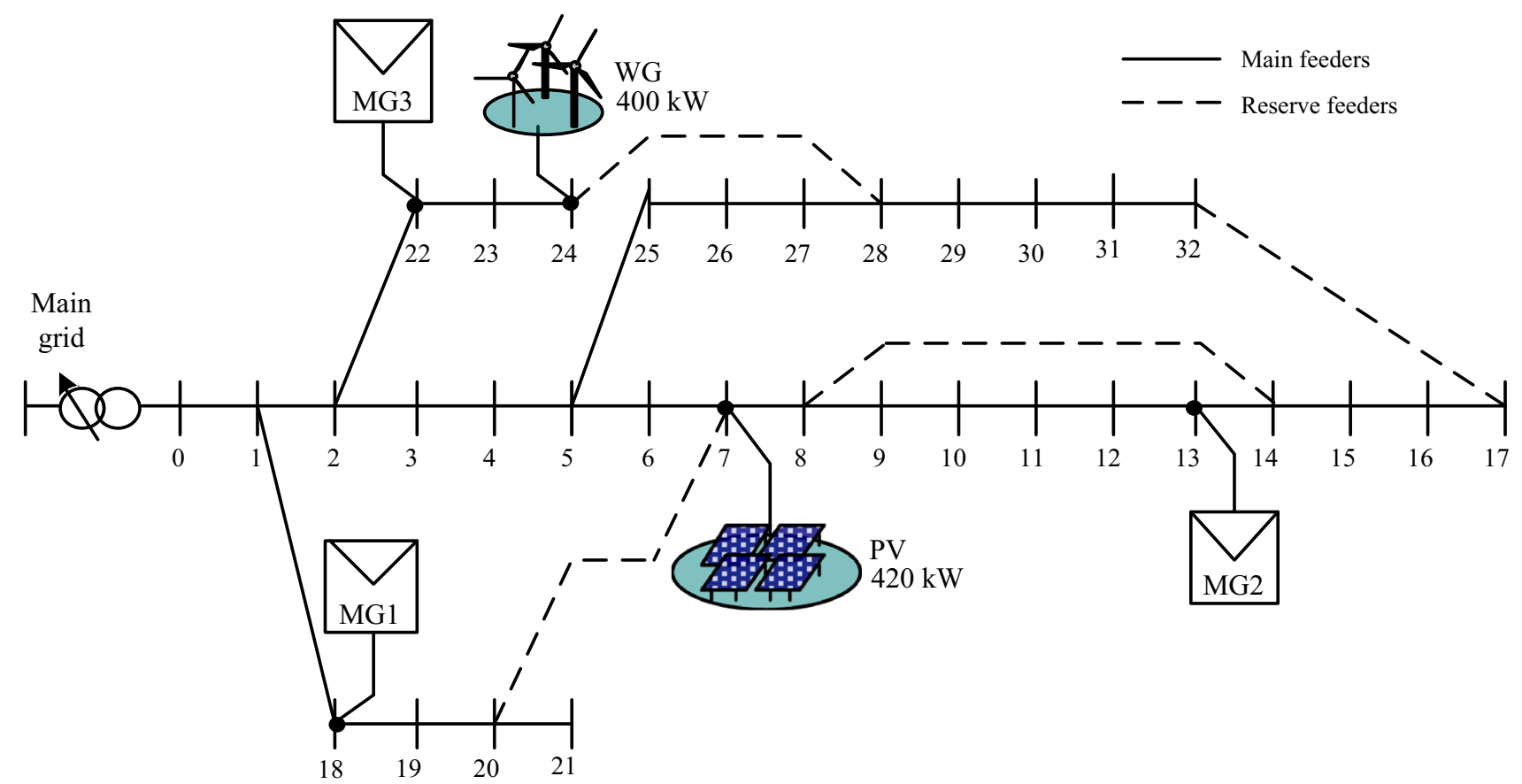

Fig. 4 Modified IEEE-33 bus benchmark distribution network 
Table 2 Technical and economic parameters of ESSs

\begin{tabular}{llll}
\hline Parameter & LAB & NaS & LIB \\
\hline PCS (¥/kW) & 2835 & 2745 & 3472.5 \\
Storage section (¥/kWh) & 4635 & 2145.6 & 5962.5 \\
Fixed O\&M (¥/kW) & 25.5 & 27 & 51.75 \\
Variable O\&M (¥/MWh) & 2.775 & 13.5 & 15.75 \\
Efficiency (\%) & 0.80 & 0.85 & 0.90 \\
Range of SOC (\%) & $30-70$ & $10-90$ & $20-80$ \\
Lifetime (yr) & 10 & 15 & 12.5 \\
\hline
\end{tabular}

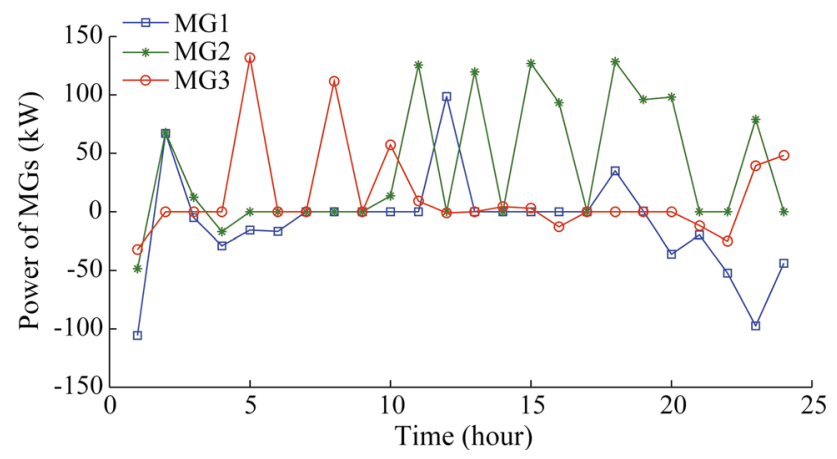

Fig. 6 Curves of 24h outputs of MGs in typical daily scenarios

\subsection{Results of typical daily scenarios}

1) Power output characteristics of MGs

Based on Section 3.1, power characteristics of MGs are calculated. Curves of active power are shown in Fig. 6.

These curves indicate different variation trends based on load demands and allocations of different MGs. These zero points of these curves mean self-sufficiency situations based on the dynamic power regulating by the effect of DESSs in MGs.

2) Establishment results of typical daily scenarios

Based on Section 3.2, considering weather conditions, the annual prediction data of WG, PV and load demand are calculated by models of PV and WT in [32] and [33], and clustered into four types by FCM, shown as Fig. 7.

Then, based on the clustering centers and corresponding probabilities, the typical daily scenarios consisting of REGs and load are established by the multiple scenarios technique, and these most likely 10 scenarios are selected, as shown in Table 3.

\subsection{Case study}

1) Case 1

In Case 1, minimizing the total costs is selected to be the objective of the upper level from (22). Based on the three

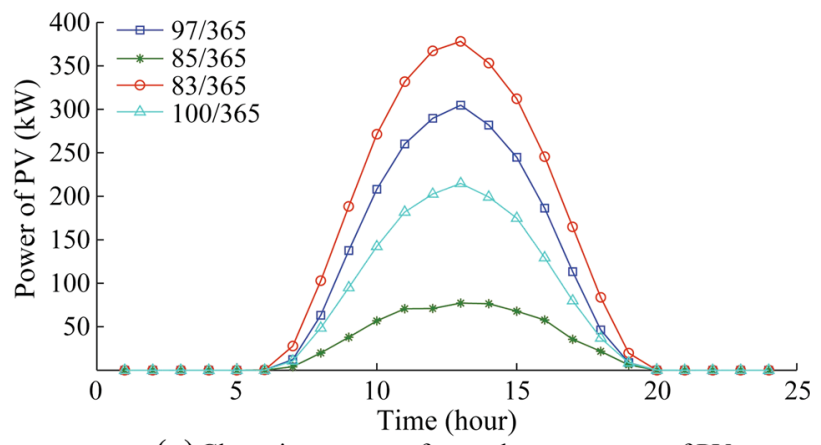

(a) Clustering centers of annual power output of PV

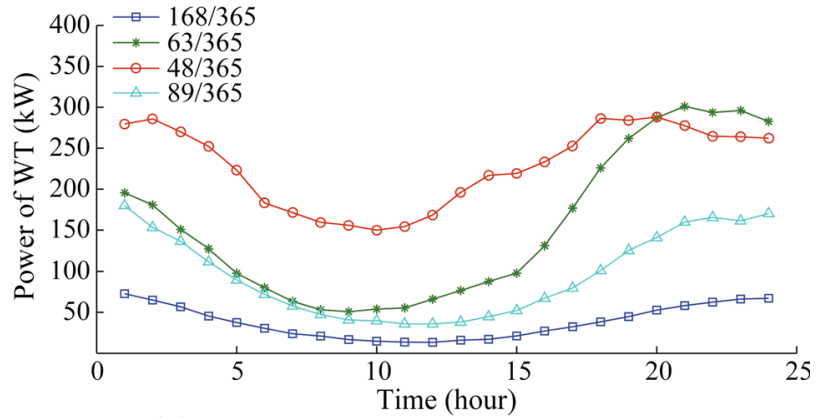

(b) Clustering centers of annual power output of WT

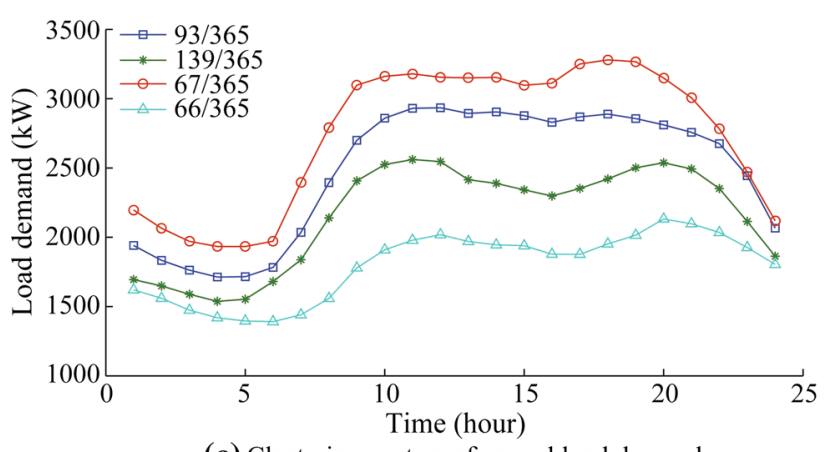

(c) Clustering centers of annual load demand

Fig. 7 Clustering centers of annual power output of PV, WT and load

Table 3 Scenarios and corresponding probabilities

\begin{tabular}{llllll}
\hline Scenario & 1 & 2 & 3 & 4 & 5 \\
\hline Scheme & PV 1 & PV 2 & PV 3 & PV 4 & PV 1 \\
& WT 1 & WT 1 & WT 1 & WT 1 & WT 1 \\
& Load 1 & Load 1 & Load 1 & Load 1 & Load 2 \\
Prob. & 0.0909 & 0.0797 & 0.0778 & 0.0938 & 0.1359 \\
\hline Scenario & 6 & 7 & 8 & 9 & 10 \\
\hline Scheme & PV 2 & PV 3 & PV 4 & PV 1 & PV 4 \\
& WT 1 & WT 1 & WT 1 & WT 4 & WT 4 \\
& Load 2 & Load 2 & Load 2 & Load 2 & Load 2 \\
Prob. & 0.1191 & 0.1163 & 0.1401 & 0.0720 & 0.0742 \\
\hline
\end{tabular}


Table 4 Optimal schemes and costs of ESS in Case 1

\begin{tabular}{lllll}
\hline Parameter & LAB & NaS & LIB & None \\
\hline Bus & 31 & 8 & 31 & - \\
$P_{\text {rate }}(\mathrm{kW})$ & 500 & 500 & 500 & 0 \\
$E_{\text {rate }}(\mathrm{kWh})$ & 500 & 500 & 500 & 0 \\
$C_{\text {cap,d }}\left(10^{3} ¥\right)$ & 1.53 & 0.78 & 1.67 & - \\
$C_{\text {FOM\&VOM,d }}(¥)$ & 68.22 & 198.95 & 259.85 & - \\
$C_{\text {load,d }}\left(10^{3} ¥\right)$ & 44.49 & 44.33 & 44.30 & 44.39 \\
$C_{\text {loss }, \mathrm{d}}\left(10^{3} ¥\right)$ & 1.52 & 1.51 & 1.52 & 1.52 \\
$B_{\text {def,d }}(¥)$ & 2.39 & 5.43 & 3.64 & - \\
$C_{\text {total,d }}\left(10^{3} ¥\right)$ & 47.60 & 46.81 & 47.74 & 45.91 \\
\hline
\end{tabular}

types of ESS, different planning results are provided in Table 4.

As Table 4 shows, power ratings and energy capacities of ESS tend to lower bounds, no matter which type the ESS is. This is because that the diurnal capital cost and the O\&M costs of ESS are much greater than extra benefits obtained by the arbitrage alone. In other words, the diurnal capital cost and the O\&M costs of ESS play a decisive role in the planning process.

Based on these planning schemes in Case 1, power curves of net load in Scenario 5 with the largest probability of occurrence are shown in Fig. 8. Due to the small power ratings and energy capacities, these three ESSs have small effects on peak load shaving and valley load filling, which is also indicated by the benefits of upgrade deferral shown in Table 4.

2) Case 2

In Case 2, minimizing the diurnal operating costs of regional ADS from (18) and (19). Three different planning results are shown in Table 5.

In Case 2, due to taking no account of costs of ESS, optimal results tend to the upper bounds of power rating and energy capacity to obtain more extra benefits by the arbitrage. Power curves of net load in Scenario 5 are shown in Fig. 9.

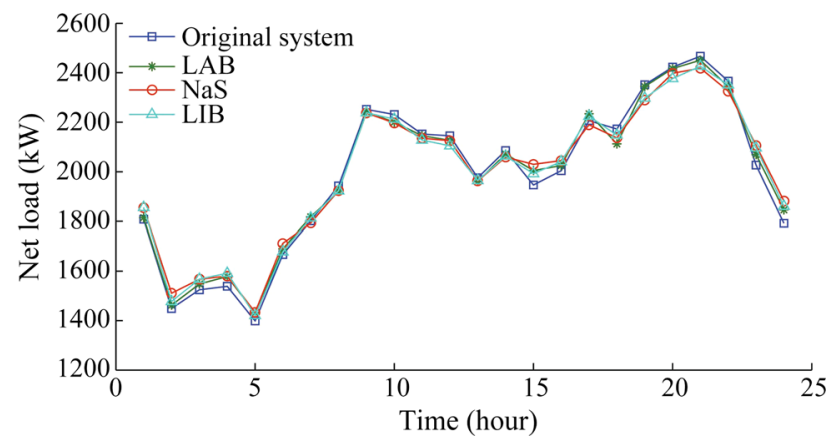

Fig. 8 Power curves of net load of Case 1 in Scenario 5
Table 5 Optimal schemes and costs of ESS in Case 2

\begin{tabular}{lllll}
\hline Parameter & LAB & NaS & LIB & None \\
\hline Bus & 27 & 23 & 32 & - \\
$P_{\text {rate }}(\mathrm{kW})$ & 1000 & 1000 & 1000 & 0 \\
$E_{\text {rate }}(\mathrm{kWh})$ & 3000 & 3000 & 3000 & 0 \\
$C_{\text {cap,d }}\left(10^{3} ¥\right)$ & 6.83 & 2.94 & 7.58 & - \\
$C_{\text {FOM\&VOM,d }}(¥)$ & 136.45 & 397.91 & 519.71 & - \\
$C_{\text {load,d }}\left(10^{3} ¥\right)$ & 44.00 & 43.62 & 43.63 & 44.39 \\
$C_{\text {loss,d }}\left(10^{3} ¥\right)$ & 1.50 & 1.49 & 1.50 & 1.52 \\
$B_{\text {def,d }}(¥)$ & 47.49 & 53.20 & 53.33 & - \\
$C_{\text {ope,d }}\left(10^{3} ¥\right)$ & 45.50 & 45.11 & 45.13 & 45.91 \\
$C_{\text {total,d }}\left(10^{3} ¥\right)$ & 52.42 & 48.39 & 53.18 & 45.91 \\
\hline
\end{tabular}

From Fig. 9, it can be seen that ESSs keep charging during valley hours and discharging during peak hours. And these ESSs have recommendable effects on peak load shaving and valley load filling.

Nevertheless, it can be noted that the diurnal costs of ESS rise dramatically. Taking LIB as an example, compared to the ADS without ESS, the total costs of ADS with LIB experience a drastic increase from $45.91 \times 10^{3}$ to $53.18 \times 10^{3}$. However, the extra benefits obtained by the arbitrage $\left(0.78 \times 10^{3}\right)$ are much smaller than the costs of LIB $\left(8.10 \times 10^{3}\right)$. Consequently, benefits obtained by the arbitrage alone are not big enough to achieve profitability under the current technical and economic conditions.

Meanwhile, the ADS with LIB spends more than twice as much cost on the installation, O\&M of ESS as the ADS with $\mathrm{NaS}$ does. It suggests that the $\mathrm{NaS}$ has more economic efficiency than other two types of ESS.

3) Case 3

To reflect the influence of optimal operation on the planning scheme, besides the total costs as (22), the daily average level of peak load shaving, shown as (40), is added into the objective function of the upper level by means of a penalty function. The planning results are shown in Table 6.

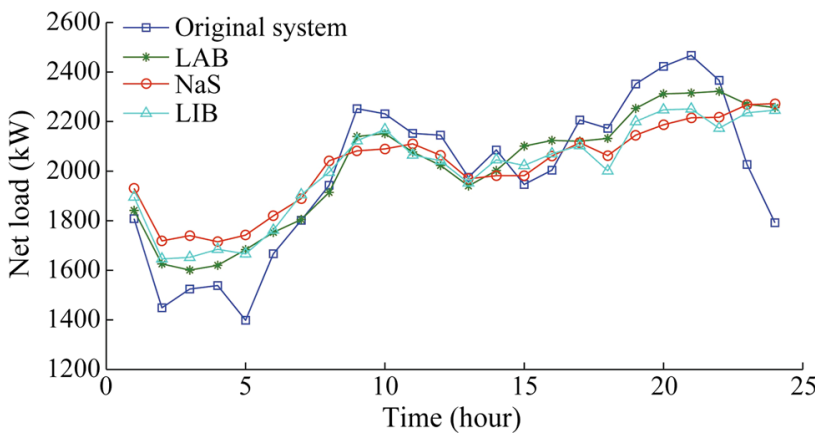

Fig. 9 Power curves of net load of Case 2 in Scenario 5 
$\lambda_{\mathrm{APLS}}=\sum_{s=1}^{S} \eta_{s} \frac{\left(P_{\mathrm{NL}, s}^{\max }-P_{\mathrm{NL}^{\prime}, s}^{\max }\right)}{P_{\mathrm{NL}, s}^{\max }}$

Compared with Case 1, power ratings and energy capacities of these ESSs all rise in different degrees. Meanwhile, due to the constraint $\lambda_{\mathrm{APLS}}$, there are more extra benefits obtained by upgrade deferral. What is more, there has been a drop in the costs of load demand and network losses, respectively.

From the comparisons among these three ESSs, it can be noted that LIB can reach the same daily average level of peak load shaving at least costs of power rating and energy capacity. However, in terms of economic efficiency, $\mathrm{NaS}$ beats LAB and LIB for the top spot again.

These power curves of net load in Case 2 shown in Fig. 10 demonstrate the commendable effects of peak load

Table 6 Optimal schemes and costs of ESS in Case 3

\begin{tabular}{lllll}
\hline Parameter & LAB & NaS & LIB & None \\
\hline Bus & 7 & 20 & 16 & - \\
$P_{\text {rate }}(\mathrm{kW})$ & 760 & 754 & 658 & 0 \\
$E_{\text {rate }}(\mathrm{kWh})$ & 2279 & 2198 & 1285 & 0 \\
$C_{\text {cap,d }}\left(10^{3} ¥\right)$ & 5.19 & 2.17 & 3.53 & - \\
$C_{\text {FOM\&VOM,d }}(¥)$ & 86.45 & 300.07 & 341.97 & - \\
$C_{\text {load,d }}\left(10^{3} ¥\right)$ & 44.24 & 43.90 & 44.22 & 44.39 \\
$C_{\text {loss,d }}\left(10^{3} ¥\right)$ & 1.50 & 1.52 & 1.51 & 1.52 \\
$B_{\text {def,d }}(¥)$ & 21.73 & 20.95 & 22.61 & - \\
$C_{\text {ope,d }}\left(10^{3} ¥\right)$ & 45.74 & 45.42 & 45.73 & 45.91 \\
$C_{\text {total,d }}\left(10^{3} ¥\right)$ & 50.99 & 47.87 & 49.58 & 45.91 \\
$\lambda_{\text {APLS }}(\%)$ & 2.5 & 2.5 & 2.5 & - \\
\hline
\end{tabular}

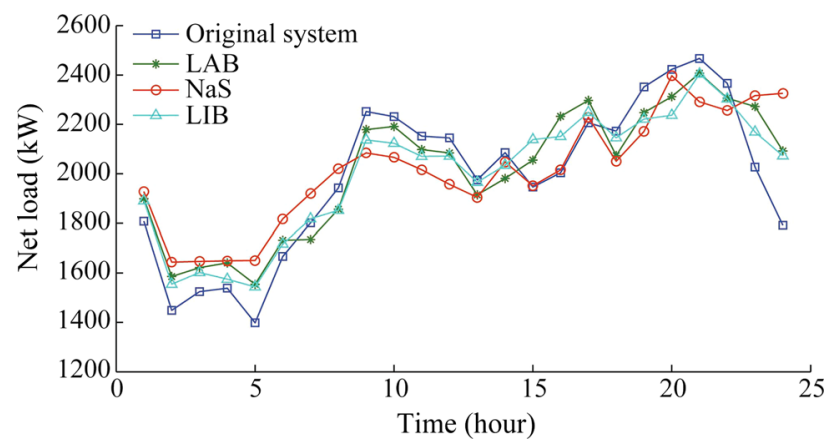

Fig. 10 Power curves of net load of Case 3 in Scenario 5

Table 7 Standard deviations of net load of Case 3 in Scenario 5

\begin{tabular}{lllll}
\hline Parameter & LAB & NaS & LIB & None \\
\hline Std & 259.9 & 224.9 & 251.8 & 311.7 \\
Range & 852.7 & 752.9 & 860.4 & 1068 \\
\hline
\end{tabular}

shifting and valley load filling. Meanwhile, thanks to the fuzzy satisfaction-maximizing method, the fluctuations of all these curves with the integration of ESS decrease in different degrees, as shown in Table 7.

Reserve capabilities of these ESSs are demonstrated in Fig. 11.

As can be seen from the curves, ESSs can provide power supply to the essential load and be ready to participate in the system service restoration, while fulfilling other two tasks. Planning schemes and technical features contribute to the differences of the reserve ability. NaS leads in the reserve capability among these three ESSs due to the biggish energy capacity and the wide permissible range of SOC.

4) Case 4

To reflect the influence of planning scheme on the optimal operation clearly, operation conditions of $\mathrm{NaS}$ in these three cases are selected for analyses. The power curves, SOC curves, and reserve capabilities of NaS are demonstrated from Fig. 12 to Fig. 14, respectively.

It is noted that $\mathrm{NaS}$ in Case 2 has the largest scope of power variation because of the largest power rating and energy capacity, which means the strongest ability of power regulation. Meanwhile, we also find that the discharging power outputs in Case 1 fluctuate around $25 \mathrm{~kW}$ during TOU peak time 10 to 13 , and hit a low of $5.99 \mathrm{~kW}$ at time 13 , which means that the $\mathrm{NaS}$ has a small effect on

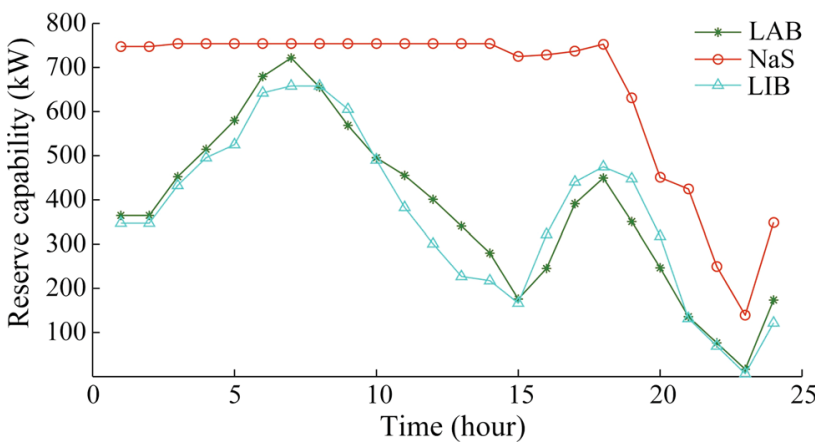

Fig. 11 Reserve capability of ESS in Scenario 5

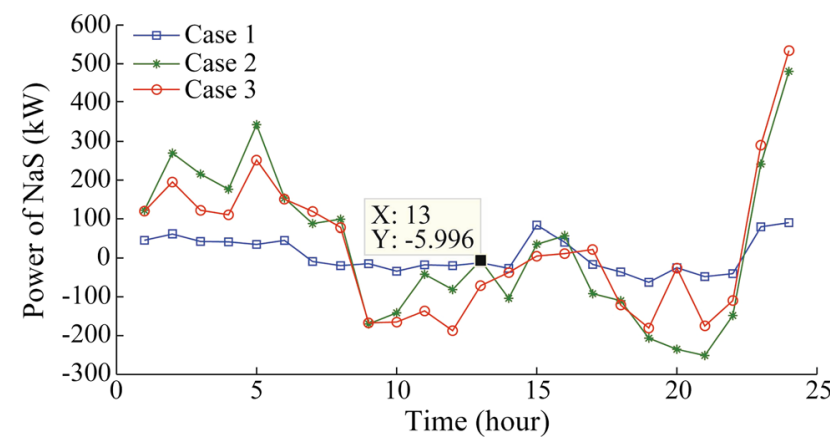

Fig. 12 Power of NaS in Scenario 5 


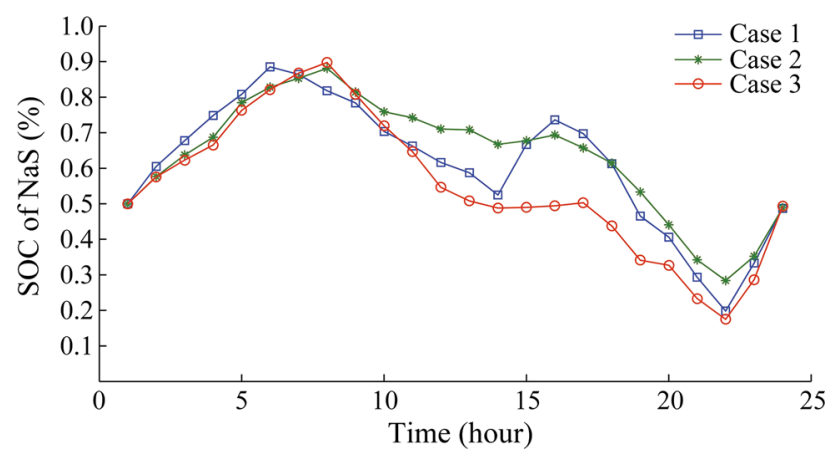

Fig. 13 SOC of NaS in Scenario 5

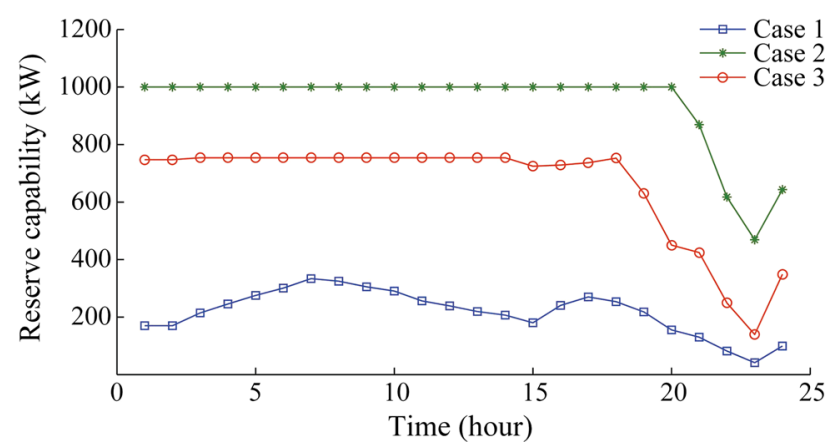

Fig. 14 Reserve capability of $\mathrm{NaS}$ in Scenario 5

peak load shaving during TOU peak time $10-13$ in Case 1.

As shown in Fig. 13, due to the largest installed capacity, the lowest point of SOC in Case 2 is greater than those of others. It indicates that $\mathrm{NaS}$ in Case 2 has the greatest reserve capability even after finishes the mission of peak load shaving, which is also certified by the comparison in Fig. 14. In other words, $\mathrm{NaS}$ in Case 2 can take more responsibility for system support.

What we analyze above suggests that the planning model proposed in this work can integrate the operation stage into account effectively, and the fuzzy multi-objective model in the lower level is an effectual operation strategy for ESS.

5) Case 5

Figure 15 shows convergence characteristics of searching for the minimum costs in Case 3 by MHCDEPSO, chaos DE and chaos PSO.

It is also noteworthy that the hybrid algorithm can converge to its best solution at the $17^{\text {th }}$ iteration, which is the smallest number of iterations among these algorithms. Meanwhile, MHCDEPSO can converge to a better optimal solution $\left(47.87 \times 10^{3}\right)$ than chaos PSO $\left(48.14 \times 10^{3}\right)$ and chaos DE $\left(48.30 \times 10^{3}\right)$. The results verify the availability and effectiveness of the proposed hybrid algorithm.

Additionally, to investigate the robustness of the proposed algorithm, Case 3 is carried out 30 times

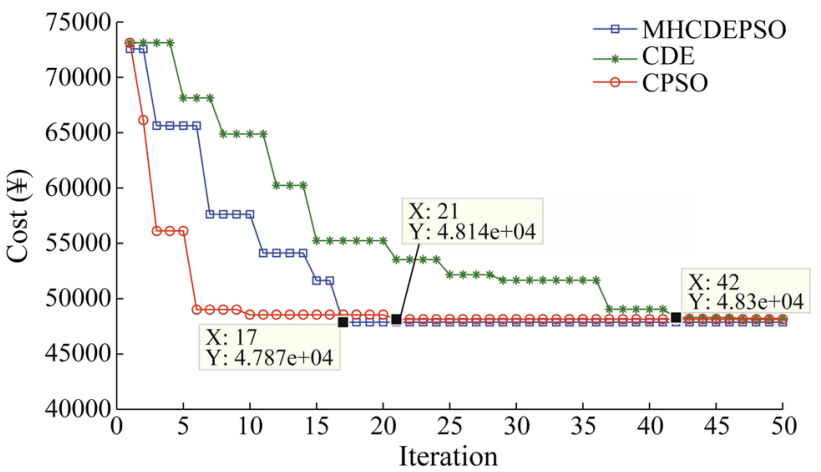

Fig. 15 Convergence characteristics of MHCDEPSO, CDE, and CPSO

Table 8 Results based on 30 independent runs by MHCDEPSO

\begin{tabular}{lllll}
\hline MHCDEPSO & \multicolumn{2}{l}{ Cost $\left(10^{3} ¥\right)$} & Std \\
\cline { 2 - 4 } & Max & Min & Average & \\
\hline & 47.8905 & 47.8640 & 47.8800 & 6.7541 \\
\hline
\end{tabular}

independently. The maximum, minimum, average and standard deviation values of total costs are provided in Table 8 . These results show the robustness and reliability of the proposed hybrid algorithm.

\section{Conclusion}

In this paper, we propose a fuzzy multi-objective bilevel formulation of ESS planning problem in ADSs. A multi-subgroup hierarchical chaos hybrid algorithm is developed to deal with the bi-level mixed integer optimization problem.

Based on the simulation results and discussions, several final remarks and conclusions can be drawn as follows.

1) By means of the bi-level optimization, the proposed planning model enables us to take full consideration of the operation strategy of ESS, which contributes to obtaining a more reasonable planning scheme.

2) By means of FCM and the multiple scenarios technique, annual time-dependent forecasting data of REGs and load demand can be processed into typical daily scenarios effectively. These scenarios can capture the time-variable nature of REGs and load demand, and ease the computational burden.

3) Based on the current economic and technological conditions of ESS, the costs of ESS play a decisive role in the planning process of ESS in ADSs. But, the integrating of ESSs will also bring other additional value.

Acknowledgements This work was supported by Application Technology Research and Engineering Demonstration Program of National Energy Administration in China (No. NY20150301). 
Open Access This article is distributed under the terms of the Creative Commons Attribution 4.0 International License (http:// creativecommons.org/licenses/by/4.0/), which permits unrestricted use, distribution, and reproduction in any medium, provided you give appropriate credit to the original author(s) and the source, provide a link to the Creative Commons license, and indicate if changes were made.

\section{Appendix A}

Table A1 Parameters of WG, PV and distribution equipment

\begin{tabular}{ll}
\hline Parameter & Value \\
\hline Interest rate $r$ & 0.08 \\
Rated power of WG $(\mathrm{kW})$ & 400 \\
Cut-in wind speed $(\mathrm{m} / \mathrm{s})$ & 3.5 \\
Rated wind speed $(\mathrm{m} / \mathrm{s})$ & 12 \\
Cut-out wind speed $(\mathrm{m} / \mathrm{s})$ & 20 \\
Rated power of PV $(\mathrm{kW})$ & 420 \\
Inverter efficiency $(\%)$ & 17.1 \\
Area of per panel $\left(\mathrm{m}^{2}\right)$ & 1.6335 \\
Rated power of per panel $(\mathrm{kW})$ & 0.28 \\
Capital cost of equipment in substation $(¥ / \mathrm{kW})$ & 888 \\
Capital cost of equipment in lines $(¥ / \mathrm{kW})$ & 474 \\
Contract price of $W G$ and $\mathrm{PV}(¥ / \mathrm{kWh})$ & 0.414 \\
\hline
\end{tabular}

Table A2 TOU price of various stages of implementation

\begin{tabular}{llll}
\hline Parameter & Peak & Flat & Valley \\
\hline Period (hour) & $10-15,18-21$ & $07-10,15-18,21-23$ & $23-07$ \\
Price (¥/kWh) & 1.3222 & 0.8395 & 0.3818
\end{tabular}

Table A3 Parameters of MHCDEPSO and CPSO

\begin{tabular}{llll}
\hline MHCDEPSO & \multicolumn{3}{c}{ CPSO } \\
\hline$c_{1}$ & 2.05 & $c_{1}$ & 2.05 \\
$c_{2}$ & 2.05 & $c_{2}$ & 2.05 \\
PopSize & 9 & PopSize & 30 \\
$w_{\max }$ & 0.9 & $w_{\max }$ & 0.9 \\
$w_{\min }$ & 0.4 & $w_{\min }$ & 0.4 \\
$k_{\max }$ & 50 & $k_{1 \max }$ & 300 \\
$F$ & 1.5 & $k_{2 \max }$ & 300 \\
$C R_{\max }$ & 0.85 & - & - \\
$C R_{\min }$ & 0.25 & & \\
$\lambda$ & 2 & & - \\
$M$ & 5 & - & - \\
SubgropeSize & 3 & - & \\
\hline
\end{tabular}

\section{References}

[1] Hatziargyriou N, Asano H, Iravani R et al (2007) Microgrids. IEEE Power Energy Mag 5(4):78-94

[2] Moghaddam AA, Seifi A, Niknam T et al (2011) Multi-objective operation management of a renewable MG (micro-grid) with back-up micro-turbine/fuel cell/battery hybrid power source. Energy 36(11):6490-6507

[3] Liu JY, Gao HJ, Ma Z et al (2015) Review and prospect of active distribution system planning. J Mod Power Syst Clean Energy 3(4):457-467. doi:10.1007/s40565-015-0170-7

[4] Daghi M, Sedghi M, Ahmadian A et al (2016) Factor analysis based optimal storage planning in active distribution network considering different battery technologies. Appl Energy 183:456-469

[5] Lü TG, Ai Q, Sun SM et al (2016) Behavioural analysis and optimal operation of active distribution system with multi-microgrids. Proc CSEE 36(1):122-132

[6] Hossein F, Mahmud FF, Moein MA (2017) Enhancing power system resilience through hierarchical outage management in multi-Microgrids. IEEE Trans Smart Grid 7(6):2869-2879

[7] Miranda I, Leite H, Silva N et al (2016) Coordination of multifunctional distributed energy storage systems in distribution networks. IET Gener Transm Distrib 10(3):726-735

[8] Chen JC, Song XD (2015) Economics of energy storage technology in active distribution networks. J Mod Power Syst Clean Energy 3(4):583-588. doi:10.1007/s40565-015-0148-5

[9] Xu L, Ruan XB, Mao CX et al (2012) An improved optimal sizing method for wind solar battery hybrid power system. IEEE Trans Sustain Energy 4(3):774-785

[10] Chen CS, Duan SX, Cai T et al (2011) Optimal allocation and economic analysis of energy storage system in microgrids. IEEE Trans Power Electron 26(10):2762-2773

[11] Kerdphol T, Fuji K, Mitani Y et al (2016) Optimization of a battery energy storage system using particle swarm optimization for stand-alone microgrids. Int J Electr Power Energy Syst 81:32-39

[12] Camargo NCE, Vidotto ML, Krauss NR et al (2014) Sizing and simulation of a photovoltaic-wind energy system using batteries, applied for a small rural property located in the south of Brazil. Renew Sustain Energy Rev 29(7):151-157

[13] Atwa YM, El-Saadany EF (2010) Optimal allocation of ESS in distribution systems with a high penetration of wind energy. IEEE Trans Power Syst 25(4):1815-1822

[14] You Y, Liu D, Zhong Q et al (2014) Multi-objective optimal placement of energy storage systems in an active distribution network. Autom Electr Power Syst 38(18):46-52. doi:10.7500/ AEPS20130722009

[15] Xiao J, Zhang ZQ, Bai LQ et al (2016) Determination of the optimal installation site and capacity of battery energy storage system in distribution network integrated with distributed generation. IET Gener Transm Distrib 10(3):601-607

[16] Zhang YX, Dong ZY, Luo FJ et al (2016) Optimal allocation of battery energy storage systems in distribution networks with high wind power penetration. IET Renew Power Gener 10(8):1105-1113

[17] Sedghi M, Ahmadian A, Aliakbar-Golkar M (2015) Optimal storage planning in active distribution network considering uncertainty of wind power distributed generation. IEEE Trans Power Syst 31(1):304-316

[18] Ahmadian A, Sedghi M, Aliakbar-Golkar M et al (2016) Optimal probabilistic based storage planning in tap-changer equipped distribution network including PEVs, capacitor banks and WDGs: a case study for Iran. Energy 112:984-997 
[19] Hemmati R, Saboori H, Jirdehi MA (2016) Multistage generation expansion planning incorporating large scale energy storage systems and environmental pollution. Renew Energy 97:636-645

[20] Saez-De-Ibarra A, Milo A, Gaztanaga H et al (2016) Co-optimization of storage system sizing and control strategy for intelligent photovoltaic power plants market integration. IEEE Trans Sustain Energy 7(4):1749-1761

[21] Berrada A, Loudiyi K (2016) Operation, sizing, and economic evaluation of storage for solar and wind power plants. Renew Sustain Energy Rev 59:1117-1129

[22] Ghofrani M, Arabali A, Etezadi-Amoli M et al (2013) A framework for optimal placement of energy storage units within a power system with high wind penetration. IEEE Trans Sustain Energy 4(2):434-442

[23] Pilo F, Jupe S, Silvestro F et al (2014) Planning and optimization methods for active distribution systems. WG C6.19: TB 591, CIGRE, Paris, France 10(1):88-93

[24] Wen UP, Hsu ST (1991) Linear bi-level programming problems. A review. J Oper Res Soc 42(2):125-133

[25] Mukhopadhyay A, Maulik U (2009) Unsupervised pixel classification in satellite imagery using multiobjective fuzzy clustering combined with SVM classifier. IEEE Trans Geosci Remote Sens 47(4):1132-1138

[26] Zakeri B, Syri S (2015) Electrical energy storage systems: A comparative life cycle cost analysis. Renew Sustain Energy Rev 42:569-596

[27] He XH, Wang W, Jiang JC (2015) An improved artificial bee colony algorithm and its application to multi objective optimal power flow. Energies 8(4):2412-2437

[28] Xie H, Yu WK, Yang P et al (2015) Inverse kinematics solution method based on multi-subgroup hierarchical hybrid of differential algorithm and chaotic particle swarm optimization. J Electron Meas Instrum 29(10):1456-1463

[29] Xu HL, Qian X, Zhang L (2012) Study of ACO algorithm optimization based on improved tent chaotic mapping. J Inf Comput Sci 9(6):1653-1660

[30] Deng ZX, Cao DQ, Liu XJ et al (2008) New differential evolution algorithm. Comput Eng Appl 44(24): 40-42, 52

[31] Subcommittee P (1979) IEEE reliability test system. IEEE Trans Power Appar Syst PAS 98(6):2047-2054
[32] Kongnam C, Nuchprayoon S, Premrudeepreechacharn S et al (2009) Decision analysis on generation capacity of a wind park. Renew Sustain Energy Rev 13(8):2126-2133

[33] Wang HY, Zhu NH, Bai XM (2015) Reliability model assessment of grid-connected solar photovoltaic system based on Monte-Carlo. Appl Sol Energy 51(4):262-266

Rui LI received the M.Sc. degree in Electrical Engineering from Beijing Jiaotong University in 2012, where he is currently pursuing the Ph.D. degree in Electrical Engineering. Currently, his research interests include active distribution system planning and renewable energy system.

Wei WANG is a Professor with the School of Electrical Engineering and National Active Distribution Network Technology Research Center, Beijing Jiaotong University. He has authored more than 50 papers in journals and conferences. He has been a leader for over 30 applied projects. His research interests include power systems analysis and control, active distribution system technology and electrical equipment on-line monitoring and faults diagnosis technology.

Zhe CHEN is a Professor with the Department of Energy Technology, Aalborg University, Aalborg, Denmark. He has authored more than 400 research papers in journals and conferences. His research background includes power systems, power electronics and electric machines. His present main interests are wind energy and modern power systems. Prof. Chen is a Fellow of IET. He is an Associate Editor of IEEE TRANSACTIONS ON POWER ELECTRONICS.

Xuezhi WU is an Associate Professor with the School of Electrical Engineering and National Active Distribution Network Technology Research Center, Beijing Jiaotong University. He has authored more than 30 papers in journals and conferences. His research interests include topology and control of converter for renewable energy and micro-grid converter, micro-grid system control and large capacity inverter for motor control. 